\title{
Antecedents and outcomes of meaningful work among school teachers
}

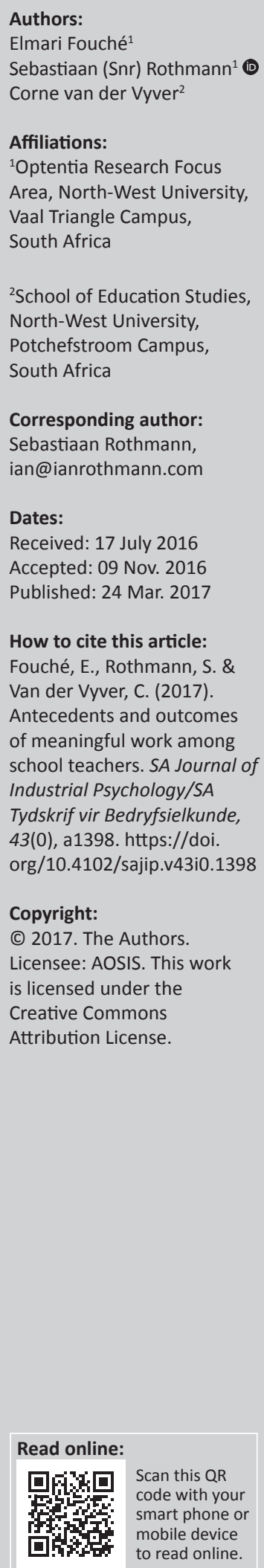

Orientation: Quality education is dependent on the well-being, engagement, performance and retention of teachers. Meaningful work might affect these employee and organisational outcomes.

Research purpose: The aim of this study was to investigate antecedents and outcomes of meaningful work among school teachers.

Motivation for the study: Meaningful work underpins people's motivation and affects their well-being and job satisfaction. Furthermore, it is a significant pathway to healthy and authentic organisations. However, a research gap exists regarding the effects of different antecedents and outcomes of meaningful work.

Research approach, design and method: A cross-sectional survey was used with a convenience sample of 513 teachers. The Work-Life Questionnaire, Revised Job Diagnostic Survey, Coworker Relations Scale, Work and Meaning Inventory, Personal Resources Scale, Work Engagement Scale, Turnover Intention Scale and a measure of self-rated performance were administered.

Main findings: A calling orientation, job design and co-worker relations were associated with meaningful work. A low calling orientation and poor co-worker relationships predicted burnout. A calling orientation, a well-designed job, good co-worker relationships and meaningful work predicted work engagement. Job design was moderately associated with self-ratings of performance. The absence of a calling orientation predicted teachers' intention to leave the organisation.

Practical/managerial implications: Educational managers should consider implementing interventions to affect teachers' calling orientation (through job crafting), perceptions of the nature of their jobs (by allowing autonomy) and co-worker relations (through teambuilding) to promote perceptions of meaningful work. Promoting perceptions of meaningful work might contribute to lower burnout, higher work engagement, better self-ratings of performance and retention of teachers.

Contribution/value-add: This study contributes to scientific knowledge regarding the effects of three antecedents, namely a calling orientation, job design and co-worker relationships on meaningful work. It also contributed to knowledge about the effects of meaningful work on employee and organisational outcomes.

\section{Introduction}

South Africa has a high-cost, low-performance education system that does not compare well with education systems in other developing countries, for example, Finland (Prew, 2011). Poor teacher well-being and performance in South Africa lead to poor educational outcomes (National Planning Commission, 2011). Some teachers spend too little time in contact with learners, possess inadequate subject knowledge and lack basic pedagogical ability. Several efforts to upgrade teachers' skills (i.e. teacher education programmes) have been largely ineffective (National Planning Commission, 2011).

The provision of quality education is a significant challenge that must be addressed in South Africa (Statistics South Africa, 2013). Quality education depends on the motivation, well-being and retention of teachers and school leaders (Louw, George \& Esterhuyse, 2011). In fact, teachers and school leaders (as opposed to systems) are crucial to driving change and shaping the teaching profession (Eyre, 2016). Schools are often the only formal service provider for young people living in socio-economically marginalised communities, uniquely positioning teachers to support positive psychosocial outcomes of youth living in adverse contexts (Liebenberg et al., 2016). 
Teachers in African countries are facing poor job conditions and high job demands (Jackson \& Rothmann, 2006; Willemse \& Deacon, 2015), and poor job conditions (Janik \& Rothmann, 2015) might lead to negative attitudes towards work as well as experiences of meaninglessness. As a result, teachers show high incidences of burnout (Fernet, Guay, Senécal \& Austin, 2012), and disengagement (Jackson, Rothmann \& Van de Vijver, 2006), and might think of leaving the education profession (Janik \& Rothmann, 2015).

In studying the functioning of teachers in secondary schools in South Africa, the emphasis could be on containing the damage and fixing weaknesses (e.g. poor performance and burnout) from a disease (negativity) model, or on actualising human potential from a positivity model (Youssef-Morgan \& Bockorny, 2014). A construct that is in line with the notion of positive functioning is meaningful work (May, Gilson \& Harter, 2004; Wrzesniewski, 2012). Matuska and Christiansen (2008) posited that meaningful work is highly relevant for functioning well under stressful conditions. Meaningful work underpins people's motivation and affects their wellbeing (Rosso, Dekas \& Wrzesniewski, 2010), flourishing (Keyes \& Annas, 2009) and work engagement (Kahn \& Heaphy, 2014), even when people are not disposed to experience positive affect (Steger, Littman-Ovadia, Miller, Menger \& Rothmann, 2013). Furthermore, it is a significant pathway to authentic organisations (Ryde \& Sofianos, 2014). People seek meaning and purpose in their lives and work (Steger, Kawabata, Shimai \& Otake, 2008). However, a lack of information exists on how teachers could work in ways that are meaningful and intrinsically motivating. Previous studies of meaningful work (e.g. Jackson et al., 2006; Janik \& Rothmann, 2015; Rothmann \& Hamkangandu, 2013) had limitations. Firstly, the conceptualisation and measurement of meaningful work did not include all the components of meaningful work, for example, meaning making and greater good motivations in addition to psychological meaningfulness (see Steger, Dik \& Duffy, 2012). Secondly, studies did not focus on different antecedents and outcomes of meaningful work for teachers in the African context.

\section{Meaningful work}

Steger et al. (2012) state that meaningful work comprises more than that which their work means to people (i.e. meaning). Their definition of meaningful work includes meaningfulness because it is significant and positive in valence. The positive valence of meaningful work has 'a eudaimonic (growth- and purpose-oriented) rather than hedonic focus' (p. 2). Steger et al. (2012) conceptualised meaningful work in terms of three dimensions, namely psychological meaningfulness, meaning making and greater good motivations. Psychological meaningfulness in work is a subjective experience that one's work matters and is significant. Meaning making through work captures the idea that work is a primary source of meaning in one's life. In this regard, meaningful work helps people in understanding their selves and the world around them. Greater good motivations reflect the desire to make a difference and to have a bigger impact on others.

Four factors could contribute to meaningful work (Pratt \& Ashforth, 2003). Firstly, work is meaningful when there is a fit between individuals and the organisation's values and mission. Secondly, the nature of the task (e.g. the significance, purposefulness and comprehensibility thereof) contributes to meaningful work. Thirdly, the camaraderie people experience in their workplace relationships results in experiences of meaningful work. Fourthly, meaningful work is associated with work beliefs, for example, whether work is believed to be a calling (Wrzesniewski, 2012; Wrzesniewski, McCauley, Rozin \& Schwartz, 1997). A strong effect of work role fit on teachers' experiences of meaningful work has been shown in the study of Janik and Rothmann (2015). Therefore, this study focused on the last three variables, namely the nature of the task, co-worker relationships and calling as a work orientation as antecedents of meaningful work.

\section{Calling as a work belief}

Beliefs about the role or function of work in life can shape the meaning of work (Wrzesniewski \& Tosti, 2005). Individuals with a calling orientation find that their work is inseparable from their life. A calling implies that people see their work as socially valuable, involving activities that may, but need not, be pleasurable. Wrzesniewski, Dekas and Rosso (2009) described callings as meaningful activities with significance for the person on a moral, social and personal level.

Work contributes to a greater good and makes the world a better place when people have a calling orientation towards their work. Work as a calling can be regarded as fulfilling a kind of duty and seeing work as a destiny (Bunderson \& Thompson, 2009). Inherent to the construct of calling is a sense of personal fulfilment and the desire to make a social contribution (Wrzesniewski, 2012). Studies confirmed that a calling orientation contributes to perceptions of meaningful work (Rothmann \& Hamukangandu, 2013) and work engagement (Van Zyl, Deacon \& Rothmann, 2010).

\section{Job design}

According to the job characteristics model (Hackman \& Oldham, 1980), various job characteristics, namely autonomy, task identity, skill variety, task significance and feedback, might affect experienced meaningfulness. Autonomy refers to using personal initiative and judgment to perform tasks. Task identity entails doing an entire piece of work from beginning to end. Skill variety relates to the complexity of competencies that an individual has to master at work. Task significance refers to the opportunity to perform significant tasks. Feedback entails knowing whether individuals perform well. High levels of these characteristics lead to experiences of meaningful work.

Research by May et al. (2004) as well as Janik and Rothmann (2015) confirmed that the above-mentioned job characteristics 
had direct positive effects on teachers' experiences of psychological meaningfulness. Also, Grant (2008) pointed out that a job that positively impacts the lives of others (which is possible in teaching jobs) will enhance its significance. Job characteristics could affect the significance of teachers' jobs as well as deepened purposes that underlie greater good motivations (Kahn \& Heaphy, 2014). Specific job characteristics might allow individuals to deepen the meaning of their work. For example, by allowing autonomy, teachers can change the quality and amount of interaction with others in their work context (Wrzesniewski, Berg \& Dutton, 2010).

\section{Co-worker relationships}

Relationships with co-workers affect individuals' experiences of meaningfulness (Dutton \& Ragins, 2007). According to Kahn and Heaphy (2014), relationships deepen the meaningfulness of work through a process of social identification. This happens when individuals' preferred identities are confirmed by their participation in desired relationships. The acceptance of the individuals by their fellow workers, which make them feel that they belong, has a significant influence on the meaningfulness individuals experience at work (Steger \& Dik, 2009). Caring and satisfying relationships with co-workers encourage a sense of connectedness, which might lead to psychological meaningfulness.

\section{Outcomes of meaningful work}

Meaningful work (or the lack thereof) has specific consequences for the individual (e.g. burnout and work engagement) as well as for the organisation (intention to leave and performance).

Burnout is a negative state of mind in working people, characterised by a lack of physical, emotional and cognitive resources (May et al., 2004; Schaufeli, 2003). Cherniss (1995, p. 185) linked burnout to the quest for meaning. Burnout can be regarded as a response to stress, but the cause thereof is a lack of meaning for suffering (Pines, 1993). Lambie (2006) found that the susceptibility to burnout is reduced in supportive environments where employees are respected and where bureaucratic hassles and administrative interference are minimised. Such an environment enables highly motivated employees to reach their goals and expectations and to achieve meaning (Pines, 1993). In contrast, a stressful environment may contribute to a sense of meaninglessness and burnout. When meaningfulness in work disappears, an existential crisis can arise, which results in burnout (Lambie, 2006).

Meaningful work has been linked to higher engagement levels (Janik \& Rothmann, 2015; May et al., 2004; Richardson \& Watt, 2006). Engagement refers to the 'harnessing of organisational members' selves to their work role by which they employ and express themselves physically, cognitively and emotionally during role performance' (Kahn, 1990, p. 694). According to the relational model of Kahn and
Heaphy (2014), deepened purposes (resulting from collective efforts, belongingness and contact with beneficiaries) lead to meaningful work, which results in work engagement. Therefore, high work engagement occurs because employees attach themselves to their work roles when they experience meaningful work.

Intention to leave refers to the conscious and planned willingness of an employee to leave an organisation (Chang, Wang \& Huang, 2013). Intention to leave occurs because of mental withdrawal behaviour. Humphrey, Nahrgang, and Morgeson (2007) found that workplace attributes predict intention to leave. Studies confirmed that job design (Searle \& Parker, 2013) and relationships with co-workers (Rothmann, Diedericks \& Swart, 2013) affect employees' intention to leave the organisations. An enriched job, supportive coworker relationships and having a calling will reduce the intention to leave by encouraging and sustaining a sense of meaningful work.

Self-rated performance is defined as an individual's reflection on their efficacy using an evaluation of their thoughts and actions (Bandura, 2008). Employees experiencing their jobs as negative and less meaningful will be less prone to believe in their ability to achieve challenging work goals and as a result not perform at their best (Searle \& Parker, 2013). If employees perceive their work as meaningful, it is more likely that they will perform better (Drach-Zahavy \& Erez, 2002).

\section{Aim and hypotheses}

The objective of this study was to investigate the relations among calling as a work belief, job design, co-worker relations, meaningful work and outcomes such as burnout, work engagement, performance and intention to leave. The following hypotheses were set for this study:

Hypothesis 1: A calling orientation, good job design, co-worker relations are positively associated with meaningful work.

Hypothesis 2: A calling orientation, job design, co-worker relations, and meaningful work predict burnout.

Hypothesis 3: A calling orientation, job design, co-worker relations, and meaningful work predict work engagement.

Hypothesis 4: A calling orientation, job design, co-worker relations, and meaningful work inversely predict intention to leave.

Hypothesis 5: A calling orientation, job design, co-worker relations, and meaningful work predict self-rated performance.

Hypothesis 6: A calling orientation, job design, and co-worker relations indirectly affect burnout, work engagement, intention to leave and self-rated performance via meaningful work.

\section{Research design \\ Research approach}

We used a quantitative research approach to achieve the study objectives. More specifically, we used a cross-sectional survey design to collect data on the experiences of work 
orientation, job design, co-worker relationships, meaningful work, burnout, work engagement, intention to leave and self-ratings of performance.

\section{Method \\ Participants and setting}

The setting for this study was public secondary schools within the North West Province in South Africa. There are 334 secondary schools located in 109 cities and towns in the province. A total of 800 teachers employed in public schools in specific districts were approached to participate in this study. The number of respondents varied from 8 to 20 educators per school. A final number of 513 respondents representing 40 schools completed the survey - a response rate of $64.13 \%$. Table 1 provides a description of the characteristics of the participants.

Men comprised $38.99 \%$ of the sample and women $61.01 \%$. Participants' ages varied from 19 to 65 (mean $=42$ ). The length of service in the various schools varied from 1 year to 38 years. Black people and white people represented, respectively, $54.4 \%$ and $28.8 \%$ of the total sample. A total of $7.9 \%$ of the total sample did not want to indicate their ethnic background.

\section{Measuring instruments}

The Work-Life Questionnaire (WLQ; Wrzesniewski et al., 1997) was used to measure calling as a work belief. The WLQ is a self-report measure that aims at classifying an individual's orientation to work into three categories, namely a job, a career and calling orientation. Only eight items measuring a calling orientation were used in this study. An example item is: 'I enjoy talking about my work to others'. The items are rated on a Likert scale varying from 1 (not at all) to 4 (completely). Van Zyl et al. (2010) found

TABLE 1: Characteristics of participants $(N=513)$.

\begin{tabular}{llcr}
\hline Item & Category & Frequency & \% \\
\hline Gender & Men & 200 & 38.99 \\
& Women & 313 & 61.01 \\
& Below 23 & 9 & 1.96 \\
& $23-30$ & 97 & 21.23 \\
& $31-39$ & 70 & 15.32 \\
& $40-45$ & 113 & 24.73 \\
Job level & $46-55$ & 118 & 25.82 \\
& Over 55 & 50 & 10.94 \\
& Student teacher & 19 & 3.91 \\
Years in teaching & Junior teacher & 67 & 13.79 \\
& Senior teacher & 330 & 67.90 \\
& Head of Department & 70 & 14.40 \\
& $1-2$ & 36 & 9.16 \\
& $3-5$ & 44 & 11.20 \\
& $6-10$ & 77 & 19.59 \\
& $11-20$ & 121 & 30.79 \\
& 21-30 & 84 & 21.37 \\
Home language & More than 30 years & 31 & 7.89 \\
& Afrikaans & 222 & 57.66 \\
& English & 31 & 8.05 \\
& Setswana & 132 & 34.29 \\
\hline
\end{tabular}

support for the validity and reliability of the WLQ. The internal consistency of the scale which measures a calling orientation was 0.74 .

The Revised Job Diagnostic Survey (JDS; Idaszak \& Drasgow, 1987) was used to measure individuals' reactions to job characteristics. The JDS consists of nine items. It measures autonomy (e.g. 'The job gives me a chance to use my personal initiative and judgment in carrying out the work'), task identity (e.g. 'The job is arranged so that I can do an entire piece of work from beginning to end'), skill variety (e.g. 'The job requires me to use a number of complex or high-level skills'), task significance (e.g. 'The job itself is very significant and important in the broader scheme of things') and feedback (e.g. 'After I finish a job, I know whether I performed well'). It uses a Likert-type scale anchored at extreme values of 1 (very inaccurate) and 7 (very accurate). In this study, the reliability coefficient for the JDS was 0.85 .

Co-worker relations were measured using the Co-worker Relations Scale (CRS; May et al., 2004). Six items were used (e.g. 'My interactions with my co-workers are rewarding'). The items are rated on a seven-point Likert scale ranging from 1 (strongly disagree) to 7 (strongly agree). Rewarding coworker relations can create an experience of belonging and care, which can lead to experiences of feeling safer at work (Olivier \& Rothmann, 2007). May et al. (2004) found a Cronbach's alpha coefficient of 0.93 for the CRS.

The Work and Meaning Inventory (WAMI; Steger et al., 2012) was used to measure meaningful work. The WAMI consists of 10 items which measure three subscales, namely positive meaning (four items, e.g. 'I understand how my work contributes to my life's meaning'), meaning making through work (three items, e.g. 'I view my work as contributing to my personal growth') and greater good motivations (three items, e.g. 'The work I do serves a greater purpose'). Reliabilities varying from 0.82 to 0.89 were obtained for the subscales and 0.93 for the total score. Steger et al. (2012) found strong evidence for the construct validity of the inventory.

Burnout was measured using nine items from the Personal Resources Scale (PRS; May et al., 2004). The PRS measures three dimensions of burnout, namely cognitive weariness (three items, e.g. 'I find it difficult to focus my attention while at work'), physical exhaustion (three items, e.g. 'I feel emotionally drained from my work') and emotional exhaustion (three items, e.g. 'I tend to postpone discussing touchy topics'). Olivier and Rothmann (2007) found support for the validity and reliability of the PRS. The internal consistency of the scale which measures burnout was 0.99 .

The Work Engagement Scale (WES; Diedericks \& Rothmann, 2013) was applied to measure work engagement. The WES has 13 items. A seven-point frequency scale varying from 1 (almost never or never) to 7 (always or almost always) was used for all items. The three components of Khan's (1990) conceptualisation of engagement are reflected in the items, 
namely cognitive, emotional and physical engagement. Evidence for the construct validity of the WES was reported by Diedericks and Rothmann (2013) and an alpha coefficient of 0.72 was reported for the WES.

Two items of the Turnover Intention Scale (TIS) (Diedericks, 2012) were used to measure intention to leave. An example of an item is 'If I were completely free to choose I would leave this job'. Response options ranged from 1 (strongly disagree) to 5 (strongly agree). The authors found an alpha coefficient of 0.83 for the TIS. Diedericks (2012) found an alpha coefficient of 0.79 for the TIS in a study in South Africa.

A questionnaire was compiled to measure self-rated performance. A 10-point Likert scale varying from 1 (low) to 10 (high) was used. Four items were used: (1) 'How would you rate your performance/effectiveness compared to your peers?' (2) 'How would you rate your customer care compared to that of your peers?' (3) 'How would you rate the quality of the service that you render compared to your peers?' (4) 'How would you rate your competence in your work compared to your peers?' The self-rated job performance scale had an internal consistency of 0.93 .

\section{Research procedure}

Ethical approval for this study was obtained from the Ethics Committee at the university where the research was undertaken. Permission for the study was granted by the director of the district and the school principals where participants were employed. A cover letter explaining the purpose of the survey, emphasising the confidentiality of the research project, accompanied the questionnaire. The survey included a consent letter, which was completed by all participants. Participation in the project was voluntary. Participants completed the questionnaires in hard copy format and the researcher captured responses in an Excel sheet, after which it was prepared for analysis with Mplus 7.31.

\section{Data analysis}

We performed latent variable modelling using Mplus version 7.31 (Muthén \& Muthén, 1998-2014) to test the measurement and structural models. Latent variable modelling reduces bias that originates from measurement error and makes it possible to test direct and indirect effects (Wang \& Wang, 2012). A weighted least squares with mean and variance adjustment (WLSMV) estimator was used to test the models. This estimator is robust; it does not assume normally distributed variables, and it provides the best option for modelling categorical data. The following Mplus fit indices were used in this study: absolute fit indices, which included the chi-square statistic (the test of absolute fit of the model), the weighted root mean square residual (WRMR) and the root mean square error of approximation (RMSEA); incremental fit indices, which included the Tucker-Lewis index (TLI); and the comparative fit index (CFI) (West, Taylor $\& W u, 2012)$. Criticism against the use of $\chi^{2}$ is that it is a strict test that detects trivial differences between the hypothesised model and the data. The $\chi^{2}$ test is often not of general interest when the fit of models is tested. Various practical fit indices have been developed to evaluate model fit. The CFI compares the hypothesised and independent models but takes sample size into account. The TLI is a relative measure of co-variation explained by the hypothesised model. CFI and TLI values higher than 0.90 are acceptable (Wang \& Wang, 2012). Moreover, $\mathrm{Hu}$ and Bentler (1999) recommended a cut-off value of 0.95 . The RMSEA provides an indication of the overall amount of error in the hypothesised model-data fit, relative to the number of estimated parameters in the model. The RMSEA should be 0.05 or less and should not exceed 0.08 (West et al., 2012). Cut-off values recommended by $\mathrm{Hu}$ and Bentler (1999) were based on simulation studies and should be used as rough indicators only, especially when models and data further away from confirmatory factor analysis (CFA) models with complete data are studied (West et al., 2012). Raykov's (2009) CFA-based estimate of scale reliability $(\rho)$ was computed for each scale.

In assessing the practical significance of the percentage of variance explained $\left(R^{2}\right)$ by regression equations, Cohen's (1988) guidelines were used: $R^{2}=0.25$ - large effect, $R^{2}=0.09-$ medium effect, and $R^{2}<0.09$ - small effect.

\section{Results}

Firstly, the results of tests of competing measurement models are reported. Secondly, the results of alternative structural models are analysed.

\section{Testing the measurement model}

We used CFA to test three non-nested measurement models, namely a five-factor model, as well as two alternative models specified on theoretical grounds. We used WLSMV as an estimator (Muthén \& Muthén, 1998-2014). Wang and Wang (2012) recommended that the Akaike Information Criterion (AIC) and the Bayesian Information Criterion (BIC) be used to decide on the best-fitting model when non-nested models are compared. However, AIC and BIC values cannot be computed when WLSMV is used as an estimator. Therefore, we only analysed the fit of each model without directly comparing the models.

Survey items were used as indicators of first-level latent variables. Model 1 consisted of eight latent variables, namely: (1) Calling orientation (measured by means of eight items); (2) Job design (measured by means of seven items); (3) Coworker relations (measured by six items); (4) Meaningful work (measured by means of 10 items); (5) Burnout (measured by means of nine items); (6) Engagement, which consisted of three first-order latent variables: cognitive, emotional and physical engagement (each measured using three items); (7) Performance (measured by means of four items); and (8) Intention to leave (measured by means of two items). Latent variables in model 1 were allowed to correlate. Model 2 was specified with the eight observed variables measuring calling orientation as part of meaningful work (in total 18 items). 
The rest of the model was identical to model 1. Model 3 was identical to model 1, except that all the engagement items loaded on a single factor. Model 4 was specified with 48 observed variables, measuring one latent factor.

Table 2 presents fit statistics for the test of the various models.

Table 2 shows that although the chi-square value of model 1 was statistically significant $\left(\chi^{2}=3127.90, d f=1399, p<0.001\right)$, model 1 showed good fit on four of the five fit indices: TLI = $0.96, \mathrm{CFI}=0.96$, RMSEA $=0.05$ and WRMR $=1.41$. The standardised regression weights varied from 0.40 (for item 7 of the WLQ) to 0.93 (for item 3 of the self-rated performance measure).

\section{Testing the structural model}

Table 3 shows the reliabilities and correlations of the latent variables.

Table 3 shows scale reliabilities ranging from 0.74 to 0.93 , which indicate acceptable internal consistency of all the scales. The structural model was tested based on the measurement model. Given our interest in possible mediating effects of meaningful work, three competing models were tested. Model 1 (the direct and indirect effects model) included paths from calling orientation, job design and co-worker relations to meaningful work, burnout, work engagement, performance and intention to leave. Model 2 (the direct effects model) included paths from calling orientation, job design and co-worker relations, and meaningful work to burnout, work engagement, performance, and intention to leave. However, the paths from calling orientation, job design and co-worker relations to meaningful work were constrained to zero. Constraining paths to zero implies that no relationships are allowed between the specific variables. Model 3 (the indirect effects model) included paths from meaningful work to burnout, work engagement, performance, and intention to leave. However, the paths from calling orientation, job design and co-worker relations to burnout, work engagement, performance and intention to leave were constrained to zero. Correlations were allowed between burnout, work engagement, performance and intention to leave in all three models.

Given that the three models were nested, we used the DIFFTEST procedure available for the WLSMV estimator to test the statistical significance of the change in chi-square $\left(\Delta \chi^{2}\right)$ in Mplus (Muthén \& Muthén, 1998-2014). Table 4 shows the fit statistics and standardised regression coefficients for the three competing structural models. Table 4 indicates that model 1 was the best-fitting model compared to model $2\left(\Delta \chi^{2}=474.33, \Delta d f=3, p<0.001\right)$ and model $3\left(\Delta \chi^{2}=255.75\right.$, $\Delta d f=12, p<0.001)$.

Next, the obtained relations of the best-fitting and most parsimonious structural model (model 1) are discussed regarding the hypotheses of this study. For the portion of the model predicting meaningful work, Table 4 confirms that the direct effects of a calling orientation $(\beta=0.49, p<0.01)$, job design $(\beta=0.23, p<0.01)$ and co-worker relations $(\beta=0.21$, $p<0.01)$ were statistically significant and had the expected signs. These three independent variables explained a large proportion of the variance in meaningful work $\left(R^{2}=0.49\right)$. Hypothesis 1 is accepted. For the portion of the model predicting burnout, Table 4 demonstrates that the direct effects of a calling orientation $(\beta=-0.25, p<0.01)$ and coworker relations $(\beta=-0.19, p<0.01)$ were statistically significant and had the expected signs. These two independent variables explained a moderate proportion of the variance in burnout $\left(R^{2}=0.21\right)$. These findings provide partial support for Hypothesis 2.

For the portion of the model predicting work engagement, Table 4 explicates that the direct effects of meaningful work $(\beta=0.18, p<0.01)$, a calling orientation $(\beta=0.39, p<0.01)$,

Table 2: Fit statistics of competing measurement models $(N=513)$.

\begin{tabular}{|c|c|c|c|c|c|c|}
\hline Model & $\chi^{2}$ & $d f$ & TLI & CFI & RMSEA & WRMR \\
\hline 1 & $3127.90 *$ & 1399 & 0.96 & 0.96 & $0.05 *[0.047,0.051]$ & 1.41 \\
\hline 2 & $3611.65^{*}$ & 1406 & 0.95 & 0.95 & $0.06 *[0.053,0.057]$ & 1.60 \\
\hline 3 & 3918.63* & 1402 & 0.95 & 0.95 & $0.06 *[0.057,0.061]$ & 1.65 \\
\hline 4 & 15940.90 & 1430 & 0.70 & 0.69 & $0.14 *[0.138,0.142]$ & 4.29 \\
\hline
\end{tabular}

$*, p<0.01$.

$\chi^{2}$, chi-square statistic; $d f$, degrees of freedom; TLI, Tucker-Lewis index; CFI, comparative fit index; RMSEA, root mean square error of approximation; WRMR, weighted root mean square residual.

TABLE 3: Reliability coefficients and correlations of the scales $(N=513)$.

\begin{tabular}{|c|c|c|c|c|c|c|c|c|c|c|}
\hline Variable & Mean & $S D$ & $\rho$ & 1 & 2 & 3 & 4 & 5 & 6 & 7 \\
\hline 1. Calling orientation & $2.06(4)$ & 0.60 & 0.74 & - & - & - & - & - & - & - \\
\hline 2. Job design & $5.57(7)$ & 0.98 & 0.85 & $0.57 *$ & - & - & - & - & - & - \\
\hline 3. Co-workers & $5.47(7)$ & 1.13 & 0.93 & $0.43^{*}$ & $0.63^{*}$ & - & - & - & - & - \\
\hline 4. Meaningful work & $3.82(5)$ & 0.72 & 0.93 & $0.66 *$ & $0.57 *$ & $0.45^{*}$ & - & - & - & - \\
\hline 5. Burnout & $3.39(7)$ & 1.30 & 0.88 & $-0.41^{*}$ & $-0.34 *$ & $-0.36 *$ & $-0.36^{*}$ & - & - & - \\
\hline 6. Work engagement & $5.19(7)$ & 1.11 & 0.90 & $0.72 *$ & $0.67^{*}$ & $0.59 *$ & $0.65 *$ & $0.48 *$ & - & - \\
\hline 8. Intention to leave & $2.49(5)$ & 1.21 & 0.84 & $-0.66 *$ & $-0.44 *$ & $-0.38 *$ & $-0.50 *$ & $0.48 *$ & $-0.53 *$ & $-0.16 *$ \\
\hline
\end{tabular}

$*, p<0.01$.

The number in brackets indicates the maximum scale score. Calling orientation was reverse-scored so that a high score reflects a high calling orientation. 
Table 4: Fit indices and standardised path coefficients of the structural models.

\begin{tabular}{|c|c|c|c|c|}
\hline Measures & & $\begin{array}{l}\text { Direct and indirect } \\
\text { effects (Model 1) }\end{array}$ & $\begin{array}{l}\text { Direct effects } \\
\text { (Model 2) }\end{array}$ & $\begin{array}{l}\text { Indirect effects } \\
\text { (Model 3) }\end{array}$ \\
\hline \multirow[t]{7}{*}{ Fit Indices } & $\chi^{2}$ & $3127.90 * *$ & $8682.02 * *$ & $4059.99 * * *$ \\
\hline & $d f$ & 1399 & 1402 & 1411 \\
\hline & TLI & 0.96 & 0.85 & 0.95 \\
\hline & $\mathrm{CFI}$ & 0.96 & 0.84 & 0.94 \\
\hline & RMSEA & $0.06 * *$ & $0.10 * *$ & $0.06 * *$ \\
\hline & RMSEA $90 \% \mathrm{Cl}$ & {$[0.049,0.051]$} & {$[0.098,0.102]$} & {$[0.058,0.062]$} \\
\hline & WRMR & 1.41 & 3.11 & 1.82 \\
\hline \multirow[t]{3}{*}{ Direct effects on meaningful work } & Calling orientation & $0.49 * *$ & - & $0.56 * *$ \\
\hline & Job design & $0.23 * *$ & - & $0.28 * *$ \\
\hline & Co-worker relations & $0.21 * *$ & - & $0.20 * *$ \\
\hline \multirow[t]{3}{*}{ Direct effects on burnout } & Meaningful work & -0.08 & $-0.36 * *$ & $-0.45 * *$ \\
\hline & Calling orientation & $-0.25 * *$ & $-0.30 * *$ & - \\
\hline & Job design & -0.04 & -0.05 & - \\
\hline \multirow[t]{4}{*}{ Direct effects on work engagement } & Meaningful work & $0.18 * *$ & $0.65 * *$ & $0.81 * *$ \\
\hline & Calling orientation & $0.39 * *$ & $0.48^{* *}$ & - \\
\hline & Job design & $0.21 * *$ & $0.26 * *$ & - \\
\hline & Co-worker relations & $0.21 * *$ & $0.22^{* *}$ & - \\
\hline \multirow[t]{4}{*}{ Direct effects on performance } & Meaningful work & -0.05 & $0.27 * *$ & $0.40 * *$ \\
\hline & Calling orientation & -0.13 & 0.10 & - \\
\hline & Job design & $0.42 * *$ & $0.41 * *$ & - \\
\hline & Co-worker relations & -0.01 & -0.02 & - \\
\hline \multirow[t]{4}{*}{ Direct effects on intention to leave } & Meaningful work & -0.09 & $-0.50 * *$ & $-0.61 * *$ \\
\hline & Calling orientation & $0.55 * *$ & $-0.59 * *$ & - \\
\hline & Job design & -0.03 & -0.05 & - \\
\hline & Co-worker relations & -0.08 & $-0.09 *$ & - \\
\hline
\end{tabular}

$*, p<0.05 ; * *, p<0.01$.

$d f$, degrees of freedom; TLI, Tucker-Lewis index; CFI, comparative fit index; RMSEA, root mean square error of approximation; WRMR, weighted root mean square residual.

job design $(\beta=0.21, p<0.01)$ and co-worker relations $(\beta=0.21$, $p<0.01)$ were statistically significant and had the expected signs. These four independent variables explained a large proportion of the variance in work engagement $\left(R^{2}=0.67\right)$. These findings provide partial support for Hypothesis 3. For the portion of the model predicting performance, Table 4 depicts that the direct effects of job design $(\beta=0.42, p<0.01)$ were statistically significant and had the expected sign. Job design explained a moderate proportion of the variance in performance $\left(R^{2}=0.22\right)$. These findings provide partial support for Hypothesis 4. For the portion of the model predicting intention to leave, it can be seen from Table 4 that the direct effect of a calling orientation $(\beta=-0.55, p<0.01)$ was statistically significant and had the expected sign. A low calling orientation explained a large proportion of the variance in intention to leave $\left(R^{2}=0.45\right)$. These findings provide partial support for Hypothesis 5 .

\section{Indirect effects}

To determine whether any relations in the model were indirectly affected by meaningfulness, the mediation procedure explained by Hayes (2013) was followed. Bootstrapping (with 10000 samples) was used to construct two-sided bias-corrected 95\% confidence intervals (CIs) so as to evaluate indirect effects. Lower and upper CIs are reported (see Table 5).

The indirect effect of a calling orientation on work engagement was $0.09, p<0.01$ [0.04, 0.13]. Furthermore, the indirect effect
TABLE 5: Indirect effects on burnout, work engagement, performance and intention to leave.

\begin{tabular}{lccc}
\hline Variable & \multicolumn{3}{c}{ Indirect effect } \\
\cline { 2 - 4 } & Estimate & SE & $95 \%$ BC CI \\
\hline Burnout & & & \\
Calling orientation & 0.05 & 0.04 & {$[-0.03,0.13]$} \\
Job design & -0.02 & 0.02 & {$[-0.07,0.01]$} \\
Co-worker relations & -0.01 & 0.01 & {$[-0.03,0.00]$} \\
Work engagement & & & \\
Calling orientation & $0.09 *$ & 0.03 & {$[0.04,0.13]$} \\
Job design & $0.04 *$ & 0.02 & {$[0.01,0.07]$} \\
Co-worker relations & 0.01 & 0.01 & {$[0.00,0.03]$} \\
Performance & & & \\
Calling orientation & 0.03 & 0.04 & {$[-0.09,0.17]$} \\
Job design & -0.01 & 0.02 & {$[-0.09,0.03]$} \\
Co-worker relations & -0.01 & 0.01 & {$[-0.03,0.01]$} \\
Intention to leave & & & {$[-0.05,0.19]$} \\
Calling orientation & 0.04 & 0.03 & {$[-0.12,0.01]$} \\
Job design & -0.02 & 0.02 & {$[-0.04,0.00]$} \\
Co-worker relations & -0.01 & 0.01 & \\
\hline$*, p<0.01$. & & &
\end{tabular}

$\mathrm{SE}$, Standard error; $\mathrm{Cl}$, confidence interval

of job design on work engagement was $0.04, p<0.01$ $[0.01,0.07]$. These findings provide support for Hypothesis 6 regarding two indirect effects, namely a calling orientation and job design (via meaningful work) on work engagement.

In terms of effect sizes (Cohen, 1988), the direct and indirect effects model accounts for the following percentages of the variance: Meaningful work $=51 \%$ (large effect); burnout = $39 \%$ (large effect); workengagement $=67 \%$; performance $=22 \%$ 
(moderate effect); intention to leave $=56 \%$ (large effect) These results lend empirical support for the model's fit.

\section{Discussion}

This study investigated the antecedents and outcomes of meaningful work among secondary school teachers in South Africa. The nature of the job, good co-worker relations and a calling orientation to work were related to meaningful work (Wrzesniewski et al., 1997; Wrzesniewski, 2012). A low calling orientation and poor co-worker relations predicted a moderate percentage of the variance in burnout. A calling orientation, a well-designed job, good co-worker relationships and meaningful work predicted work engagement. Job design was moderately associated with self-ratings of performance. The absence of a calling orientation predicted teachers' intention to leave the organisation.

Having a calling orientation had a direct effect on meaningful work in this study. Rothmann and Hamukangandu (2013) also found that a calling orientation contributed to perceptions of meaningful work. When teachers have a calling orientation, they will perceive their work as meaningful and impact the greater good (Willemse \& Deacon, 2015). Job design was positively associated with meaningful work. This finding is supported by Hackman and Oldham's (1980) job characteristics model. Janik and Rothmann (2015) also found a link between job design and meaningful work. Good co-worker relations were positively related to meaningful work. Steger and Dik (2009) and Wrzesniewski et al. (2003) found that employees have an interpersonal sense-making process which is the driving force for their behaviour. Good interpersonal relations enhance a person's sense of belongingness and lead to experiences of meaningfulness.

Meaningful work was negatively associated with burnout. Employees who perceive their work as meaningful are 'protected' against burnout, and it might serve as a buffer against stress. Lambie (2006) found that burnout is reduced in supportive environments where people respect each other. Meaninglessness in work results in burnout (Lambie, 2006). Meaningful work was positively associated with work engagement. The relational model of Kahn and Heapy (2014) predicts that meaningful work will contribute to the engagement.

Meaningful work was positively associated with self-rated performance. Bandura's (2008) social cognitive theory draws definite links between meaningful work and performance. According to his theory, employees act as the 'examiners' of their functioning. Employees who perceive their jobs as meaningful will be more likely to take on more challenging tasks. Thus, by expecting a positive outcome they motivate themselves to achieve their goals and, as a result, to perform better (Searle \& Parker, 2013). Drach-Zahavy and Erez (2002) found that positive self-rated performance leads to positive emotions, which in turn result in positive workplace behaviour.
A low calling orientation and poor co-worker relations predicted burnout in this study, although the effect was moderate. Teachers with a calling orientation regard their work as an inseparable part of their lives and view their jobs as significant. Therefore, if they do not have such an orientation, they lack the mechanisms to realise the significance of their jobs, a meaning making mechanism helping them to understand events in context and greater good motivations, which might result in burnout. A lack of social support from co-workers implies that they might experience a lack of care, which results in burnout (Schaufeli, 2003). Individuals who suffer from burnout might reinforce a pattern of weak support from co-workers because they might, because of their cynicism, distance themselves from others' support at work (Barkhuizen, Rothmann \& Tytherleigh, 2008).

A calling orientation, an enriched job, good co-worker relations and meaningful work predicted work engagement. Teachers with a calling orientation connect with their true selves and feel that they work for a purpose, which results in the attachment of their selves to their work roles (Kahn \& Heaphy, 2014). The effects of a calling orientation are fortified if their jobs are challenging and allow variety and autonomy, they experience co-worker support and they experience their jobs as meaningful (Richardson \& Watt, 2006). In line with the relational model of Kahn and Heaphy (2014), relationships with co-workers also predicted work engagement.

The absence of a calling orientation was strongly associated with high intention to leave. Having a calling will reduce the intention to leave by encouraging and sustaining a sense of meaningful work. Teachers wanting to make a difference in the lives of others and their learners will be less likely to leave the profession if they experience a sense of personal fulfilment in their work (Wrzesniewski \& Tosti, 2005). Teachers who see their jobs as socially valuable and derive personal satisfaction from their work will have a calling orientation and be less inclined to think of leaving an organisation.

\section{Managerial implications and recommendations}

Different methods are available to employees for enhancing the meaningfulness they experience in their work. Job crafting can be a path to meaningfulness in work contexts (Wrzesniewski et al., 2010). Employees can make adaptions in their interactions with others at work so that it can foster meaningfulness. Relationships are critical sources of meaningfulness that can be unlocked through job crafting. The primary focus of the top-down redesign approach is that of job enrichment and having fixed roles within specific jobs. To the contrary, the bottom-up job crafting perspective's primary focus is that of individual role innovation and more flexible and dynamic processes at work.

\section{Limitations of the study}

This study provided significant insights into the relationship between a calling orientation, job design, co-worker relations, meaningful work and work outcomes. However, longitudinal research is needed to understand the interplay and dynamics 
among the different constructs better. Furthermore, this study used a quantitative approach to study meaningful work. More qualitative studies regarding teachers' experiences of meaningful work and meaning making are necessary. Finally, the data used in this study were based on self-reports. More research is needed to investigate how meaningful work manifests in the behaviour of teachers.

\section{Conclusion}

The study confirmed that a calling orientation, job design, coworker relations and meaningful work affected intention to leave. From the above, it is clear that meaningful work (or the lack thereof) can have significant consequences for teachers as well as for schools. Some outcomes can be negative, for example, burnout and intention to leave. Positive results include high levels of work engagement and good performance.

\section{Acknowledgements}

\section{Competing interests}

The authors declare that they have no financial or personal relationship(s) that may have inappropriately influenced them in writing this article.

\section{Authors' contributions}

The authors contributed equally to this article.

\section{References}

Bandura, A. (2008). Re-construal of 'free will' from the agentic perspective of social cognitive theory. In J. Baer, J.C. Kaufman, \& R.F. Baumeister (Eds.), Are we free? Psychology and free will (pp. 86-127). Oxford, UK: Oxford University Press. https://doi.org/10.1093/acprof:oso/9780195189636.003.0006

Barkhuizen, N., Rothmann, S., \& Tytherleigh, M.Y. (2008). A model of work-related well-being of academic staff in a South African higher education institution South African Journal of Higher Education, 22, 404-422. https://doi.org/10.4314/ sajhe.v22ii2.25794

Bunderson, J. S., \& Thompson, J. A. (2009). The call of the wild: Zookeepers, callings, and the double-edged sword of deeply meaningful work. Administrative Science Quarterly, 54, 32-57. https://doi.org/10.2189/asqu.2009.54.1.32

Chang, W.Y., Wang, Y., \& Huang, T. (2013). Work design-related antecedents of turnover intention: A multilevel approach. Human Resource Management, 52(1) 1-26. https://doi.org/10.1002/hrm.21515

Cherniss, C. (1995). Beyond burnout: Helping teachers, nurses, therapists and lawyers recover from stress and disillusionment. New York: Routledge.

Cohen, J. (1988). Statistical power analysis for the behavioral sciences. (2nd edn.). Hillsdale, NJ: Lawrence Erlbaum Associates.

Diedericks, E. (2012). Flourishing of employees in the information technology industry in South Africa Unpublished doctoral thesis, North-West University, Vanderbijlpark, South Africa.

Diedericks, E., \& Rothmann, S. (2013). Flourishing of information technology professionals: The role of work engagement and job satisfaction. Journal of Psychology in Africa, 23, 225-234. https://doi.org/10.1080/14330237.2013.10820618

Drach-Zahavy, A., \& Erez, M. (2002). Challenge versus threat effects on the goal performance relationship. Organizational Behaviour and Human Decision Processes, 88, 667-682. https://doi.org/10.1016/S0749-5978(02)00004-3

Dutton, J.E., \& Ragins, B.R. (2007). Exploring positive relationships at work: Building a theoretical and research foundation. Mahwah, NJ: Lawrence Erlbaum Associates.

Eyre, D. (2016). High performance learning: How to become a world class school. New York: Routledge.

Fernet, C., Guay, F., Senécal, C., \& Austin, S. (2012). Predicting intra-individual changes in teacher burnout: The role of perceived school environment and motivational factors. Teaching and Teacher Education, 28, 514-525. https://doi.org/10.1016/j. tate.2011.11.013

Grant, A.M. (2008). The significance of task significance: Job performance effects, relational mechanisms, and boundary conditions. Journal of Applied Psychology, 93, 108-124. https://doi.org/10.1037/0021-9010.93.1.108

Hackman, J.R., \& Oldham, G.R. (1980). Work redesign. Reading, MA: Addison-Wesley.
Hayes, A. F. (2013). Introduction to mediation, moderation, and conditional process analysis: A regression-based approach. New York: The Guilford Press.

Hu, L.T., \& Bentler, P.M. (1999). Cut-off criteria for fit indexes in covariance structure analysis: Conventional criteria versus new alternatives. Structural Equation Modeling: A Multidisciplinary Journal, 6, 1-55. https://doi. org/10.1080/10705519909540118

Humphrey, S.E., Nahrgang, J.D., \& Morgeson, F.P. (2007). Integrating motivational, social, and contextual work design features: A meta-analytic summary and theoretical extension of the work design literature. Journal of Applied Psychology, 92, 1332-1356. https://doi.org/10.1037/0021-9010.92.5.1332

Idaszak, J.R., \& Drasgow, E. (1987). A revision of the Job Diagnostic Survey: Elimination of a measurement artifact. Journal of Applied Psychology, 72, 69-74. https://doi. org/10.1037/0021-9010.72.1.69

Jackson, L.T.B., \& Rothmann, S. (2006). Occupational stress, organisational commitment and ill health of educators in the North West Province. South African Journal of Education, 26, 75-95.

Jackson, L.T.B., Rothmann, S., \& Van De Vijver, A.J.R. (2006). A model of work-related well-being for educators in South Africa. Stress and Health, 22, 263-274. https:// doi.org/10.1002/smi.1098

Janik, M., \& Rothmann, S. (2015). Meaningful work and secondary school teachers' intention to leave. South African Journal of Education, 35, Art. \# 1008, 1-13. https://doi.org/10.15700/saje.v35n2a1008

Kahn, W. A. (1990). Psychological conditions of personal engagement and disengagement at work. Academy of Management Journal, 33, 692-724.

Kahn, W.A., \& Heaphy, E.D. (2014). Relational context of personal engagement at work. In C. Truss, R. Delbridge, E. Soane, K. Alfes, \& A. Shantz (Eds.), Employee engagement in theory and practice (pp. 163-179). London, UK: Routledge.

Keyes, C.L.M., \& Annas, J. (2009). Feeling good and functioning well: Distinctive concepts in ancient philosophy and contemporary science. Journal of Positive Psychology, 4, 197-201. https://doi.org/10.1080/17439760902844228

Lambie, G.W. (2006). Burnout prevention: A humanistic perspective and structured group supervision activity. Journal of Humanistic Counseling, Education and Development, 45, 32-44. https://doi.org/10.1002/j.2161-1939.2006.tb00003.x

Liebenberg, L., Theron, L.C., Sanders, J., Munford, R., Van Rensburg, A., Rothmann, S., et al. (2016). Bolstering resilience through teacher-student interaction: Lessons for school psychologists. School Psychology International, 37(2), 140-154. https:// doi.org/10.1177/0143034315614689

Louw, D.A., George, E., \& Esterhuyse, K. (2011). Burnout amongst urban secondary school teachers in Namibia. SA Journal of Industrial Psychology/SA Tydskrif vir Bedryf-sielkunde, 37(1), Art. \#1008, 1-7. https://doi.org/10.4102/sajip.v37i1.1008

Matuska, K.M., \& Christiansen, C.H. (2008). A proposed model of lifestyle balance. Journal of Occupational Science, 15(1), 9-19. http://doi.org/10.1080/14427591.2 008.9686602

May, D.R., Gilson, R. L., \& Harter, L.M. (2004). The psychological conditions of meaningfulness, safety and availability and the engagement of the human spirit at work. Journal of Occupational and Organizd
doi.org/10.1348/096317904322915892

Muthén, L.K., \& Muthén, B.O. (1998-2014). Mplus users' guide. (6th edn.). Los Angeles, CA: Muthén \& Muthén.

National Planning Commission. (2011). Diagnostic overview. Cape Town, South Africa: Department of the Presidency, Republic of South Africa.

Olivier, A.L., \& Rothmann, S. (2007). Antecedents of work engagement in a multinational oil company. South African Journal of Industrial Psychology, 33, 49-56. https://doi.org/10.4102/sajip.v33i3.396

Pines, A.M. (1993). Burnout: An existential perspective. In L. Goldberger \& S. Brenznits (Eds.), Handbook of stress: Theoretical and clinical aspects (2nd edn., pp. 386-402). New York: Free Press.

Pratt, M.G., \& Ashforth, B.E. (2003). Fostering meaningfulness in working and at work. In K.S. Cameron, J.E. Dutton, \& R.E. Quinn (Eds.), Positive organizational scholarship (pp. 309-327). San Francisco, CA: Berrett-Koehler Publishers.

Prew, M. (2011). Challenges facing education in South Africa. Retrieved on 12 December 2016, from http://www.cepd.org.za

Raykov, T. (2009). Evaluation of scale reliability for unidimensional measures using latent variable modeling. Measurement and Evaluation in Counseling and Development, 42, 223-232. https://doi.org/10.1177/0748175609344096

Richardson, P. W., \& Watt, H. M. G. (2006). Who chooses teaching and why? Profiling characteristics and motivations across three Australian universities. Asia-Pacific Journal of Teacher Education, 34, 27-56. https://doi/10.1080/13598660500480290

Rosso, B.D., Dekas, K.H., \& Wrzesniewski, A. (2010). On the meaning of work: A theoretical integration and review. Research in Organizational Behaviour, 30, 91-127. https://doi.org/10.1016/j.riob.2010.09.001

Rothmann, S., Diedericks, E., \& Swart, J.P. (2013). Manager relations, psychological need satisfaction and intention to leave in the agricultural sector. SA Journal of Industrial Psychology/SA Tydskrif vir Bedryfsielkunde, 39(2), Art. \#1129, 1-11. https://doi.org/10.4102/sajip.v39i2.1129

Rothmann, S., \& Hamukangandu, L. (2013). Psychological meaningfulness and work engagement among educators of Zambia. South African Journal of Education, 33 1-16. https://doi.org/10.15700/saje.v35n2a1008

Ryde, R., \& Sofianos, L. (2014). Creating authentic organizations: Bringing meaning and engagement back to work. London, UK: Kogan Page.

Schaufeli, W. B. (2003). Past and future perspectives of burnout research. South African Journal of Industrial Psychology, 29(4), 1-15. https://doi.org/10.1002/ job. 248 
Searle, B.J., \& Parker, S.K. (2013). Work design and happiness: An active, reciprocal perspective. In S.A. David, I. Boniwell, \& A. Conley Ayers (Eds.), The Oxford perspective. In S.A. David, I. Boniwell, \& A. Conley Ayers (Eds.), The Oxford
Handbook of Happiness (pp. 1-21). New York: Oxford University Press. https:// Handbook of Happiness (pp. 1-21). New York: Oxford
doi.org/10.1093/oxfordhb/9780199557257.013.0053

Statistics South Africa. (2013). General Household Survey, July 2013. Pretoria, South Africa: Statistics South Africa.

Steger, M.F., \& Dik, B.J. (2009). If one is looking for meaning in life, does it help to find meaning in work? Applied Psychology: Health and Well-being, 1, 303-320. https://doi.org/10.1111/j.1758-0854.2009.01018.x

Steger, M.F., Dik, B.J., \& Duffy, R.D. (2012). Measuring meaningful work: The Work and Meaning Inventory (WAMI). Journal of Career Assessment, 20, 322-337. https:// doi.org/10.1177/1069072711436160

Steger, M.F., Kawabata, Y., Shimai, S., \& Otake, K. (2008). The meaningful life in Japan and the United States: Levels and correlates of meaning in life. Journal of Research in Personality, 42, 660-678. https://doi.org/10.1016/j.jrp.2007.09.003

Steger, M.F., Littman-Ovadia, H., Miller, M., Menger, L., \& Rothmann, S. (2013) Engaging in work even when it is meaningless: Positive affective disposition and meaningful work interact in relation to work engagement. Journal of Caree Assessment, 21, 348-361. https://doi.org/10.1177/1069072712471517

Van Zyl, L.E., Deacon, E., \& Rothmann, S. (2010). Towards happiness: Experiences of work-role fit, meaningfulness and work engagement of industrial/organisational
psychologists in South Africa. SA Journal of Industrial Psychology/SA Tydskrif vir Bedryfsielkunde, 36(1), Art. \#890, 1-10. https://doi.org/10.4102/sajip.v36i1.89

Wang, J., \& Wang, X. (2012). Structural equation modeling: Applications using Mplus. Chichester, UK: Wiley.
West, S.G., Taylor, A.B., \& Wu, W. (2012). Model fit and model selection in structural equation modeling. In R.H. Hoyle (Ed.), Handbook of structural equation modeling (pp. 209-231). New York: The Guilford Press.

Willemse, M., \& Deacon, E. (2015). Experiencing a sense of calling: The influence of meaningful work on teachers' work attitudes. South African Journal of Industrial Psychology, 41(1), Art. \#1274, 1-9. https://doi.org/10.4102/sajip.v41i1.1274

Wrzesniewski, A. (2003). Finding positive meaning in work. In K. S Cameron, J. E. Dutton \& R. E. Quinn (Eds). The Oxford handbook of positive organizational scholarship. San Francisco, CA: Berrett-Koehler.Wrzesniewski, A. (2012). Callings. In K.S. Cameron \& G.M Spreitzer (Eds.), The Oxford handbook of positive organizational scholarship (pp. 45-56). New York: Oxford University Press.

Wrzesniewski, A., Berg, J.M., \& Dutton, J.E. (2010). Turn the job you have into the job you want. Harvard Business Review, 88(6), 114-117.

Wrzesniewski, A., Dekas, K., \& Rosso, B. (2009). Calling. In S.J. Lopez \& A. Beauchamp (Eds.), The encyclopaedia of positive psychology (pp. 115-118). Oxford, UK: Blackwell Publishing. https://doi.org/10.1002/9781444306002.ch3

Wrzesniewski, A., McCauley, C., Rozin, P., \& Schwartz, B. (1997). Jobs, careers, and callings: People's relations to their work. Journal of Research in Personality, 31, 21-33. https://doi.org/10.1006/jrpe.1997.2162

Wrzesniewski, A, \& Tosti, J. (2005). Career as a calling. In J.H. Greenhaus \& G.A Callanan (Eds.), Encyclopaedia of career development (pp. 71-74). Thousand Oaks, CA: Sage Publications.

Youssef-Morgan, C., \& Bockorny, K.M. (2014). Engagement in the context of positive psychology. In C. Truss, R. Delbridge, E. Soane, K. Alfes, \& A. Shantz (Eds.) Employee engagement in theory and practice (pp. 36-56). London, UK: Routledge. 